\title{
How important is the vertical structure for the representation of aerosol impacts on the diurnal cycle of marine stratocumulus?
}

\author{
I. Sandu ${ }^{1,2}$, J.-L. Brenguier ${ }^{1}$, O. Thouron ${ }^{1}$, and B. Stevens ${ }^{2,3}$ \\ ${ }^{1}$ CNRM-GAME, Meteo-France/CNRS, Toulouse, France \\ ${ }^{2}$ Max Planck Institute for Meteorology, Hamburg, Germany \\ ${ }^{3}$ University of California at Los Angeles, Los Angeles, CA, USA
}

Received: 19 December 2008 - Published in Atmos. Chem. Phys. Discuss.: 2 March 2009

Revised: 16 May 2009 - Accepted: 22 May 2009 - Published: 19 June 2009

\begin{abstract}
Large-Eddy Simulations (LES) are performed to examine the impact of hygroscopic aerosols on the diurnal cycle of marine stratocumulus clouds, under varying meteorological forcing conditions. When the cloud condensation nuclei concentration increase is sufficient to inhibit drizzle formation in the cloud layer, the precipitating and the nonprecipitating cloud layers exhibit contrasting evolutions, with noticeable differences in liquid water path. Aerosol-induced modifications of the droplet sedimentation and drizzle precipitation result in noticeable changes of the entrainment velocity at cloud top, but also in significant changes of the vertical stratification in the boundary layer. This set of simulations is then used to evaluate whether a model which does not explicitly represent the effects of the interactions occurring within the boundary layer on its vertical stratification (i.e. such as a mixed-layer model) is capable of reproducing at least the sign, if not the amplitude, of these aerosol impacts on the liquid water path. It is shown that the evolution of the vertical structure is key to the responses we simulate, and must be considered in bulk models that wish to predict the impact of aerosol perturbations on the radiative properties of stratocumulus-topped boundary layers.
\end{abstract}

\section{Introduction}

The significant contribution of marine stratocumulus to the Earth's radiative budget has motivated in the last decades numerous observational and modeling studies of this important cloud type. Moreover, because these shallow boundary layer

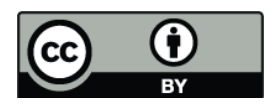

Correspondence to: I. Sandu (irina.sandu@zmaw.de) clouds are thought to be particularly sensitive to changes in the properties of the atmospheric aerosol, via the induced changes in their cloud droplet number concentration (CDNC) and their propensity to rain (i.e. aerosol indirect effects), special attention has been paid recently to their interactions with the aerosol loading. In this study, we are continuing this effort by focusing on the role played by an accurate representation of the stratocumulus-topped boundary layer's (STBL) vertical structure in the prediction of the aerosol effects on the cloud cover.

A common starting point for descriptions of the STBL is that for a bulk layer whose entire evolution is largely dictated by the energy and the moisture fluxes through the surface and the inversion layer (see, Stevens, 2005 for a review). By further assuming that the STBL is vertically uniform, or well-mixed one arrives at an effectively 0 -dimensional model first expounded by Lilly (1968). Lilly's mixed-layer (ML) theory elegantly couples the cloud, radiative and turbulent processes. The main advantage of this framework is that, while the state of the free-troposphere is known, the cloud's bulk properties (i.e. liquid water path (LWP) and geometrical thickness) and the fluxes of moisture and heat at the boundaries can be easily derived from the bulk properties of the well-mixed layer, i.e. its depth and the values of the conservative variables: the liquid water potential temperature $\theta_{l}$ and the total water content $q_{t}$. This simple framework has already been used (Nicholls, 1984; Turton and Nicholls, 1987; Bretherton and Wyant, 1997; Stevens, 2000a, 2002; Lilly, 2002; Caldwell et al., 2005; Lilly and Stevens, 2008; Lilly, 2008) to provide a deep understanding of the STBL dynamics, and recently to explore aerosol indirect effects (Zhang et al., 2005; Wood, 2007; Caldwell and Bretherton, 2009). The mixed-layer theory has also been criticized, principally because boundary layer clouds often exhibit important and

Published by Copernicus Publications on behalf of the European Geosciences Union. 
significant departures from a well-mixed state, particularly during the daytime (Nicholls, 1984), or in the presence of precipitation (Albrecht, 1993).

These criticisms resonate with recent results from largeeddy simulations (LES) which indicate that the evolution of marine stratocumulus, and more particularly their response to an increase of the aerosol loading, couples sensitively to the vertical structure of the STBL. For instance Sandu et al. (2008) showed that the differences between the diurnal cycles of a pristine precipitating and a polluted nonprecipitating marine stratocumulus are tightly related to the differing evolution of the vertical structure of the respective STBLs. The evolution of the non-precipitating STBL corroborates the widespread image of the diurnal variation of such boundary layers, wherein the boundary layer is wellmixed during night and decouples during daytime. In the precipitating case, the sedimentation of condensed water affects this evolution, so that the STBL is poorly mixed during the night, when drizzle evaporates in the entire subcloud layer, and it is less decoupled than the non-precipitating one during the day, when drizzle evaporates completely just beneath the cloud base. Two mechanisms are responsible for this modification of the STBL's evolution in the precipitating case. Thus, as earlier argued by Stevens et al. (1998) and subsequently shown by a number of others (Ackerman et al., 2004; Lu and Seinfeld, 2005; Bretherton et al., 2007; Savic-Jovcic and Stevens, 2008), the sedimentation of drizzle and cloud drops reduces the cloud top entrainment. However, the evaporative cooling of drizzle drops under the cloud base modifies the stability of the STBL (see also Feingold et al., 1996). The fluxes of heat and moisture at the boundaries of the STBL, which depend on the vertical structure of the boundary layer and on the entrainment rate, thus evolve differently in the pristine and, respectively, in the polluted case. As these fluxes control the evolution of the STBL, the two simulations diverge rapidly, although they start from the same state, and exhibit a less pronounced diurnal cycle in the pristine case.

This article builds off on this previous work and attempts to more quantitatively ask how important it is to account for the vertical structure of the STBL, which appears to be modulated by precipitation, in order to predict the contrasting evolutions of precipitating versus non-precipitating STBLs obtained with LES. In other words, we are questioning here whether a model which does not explicitly represent the effects of the interactions between drizzle evaporation, radiative transfer and dynamics on the STBL's vertical structure and coupling (i.e., the mixed-layer theory of Lilly, 1968) is at least capable of reproducing the sign and reasonably well the amplitude of the LWP response to modifications of the precipitation process and the contrasting time evolutions of the two STBLs. While it may be clear that the assumption of well-mixedness will distort the structure of the cloud layer for boundary layers that are not well-mixed, it is by no means clear that such distortions will also be apparent in the differential response of the boundary layer to different aerosol concentrations.

Our methodology is the following. First, we perform three pairs of $72 \mathrm{~h}$ LES of pristine precipitating and polluted nonprecipitating STBLs, which cover a broad range of meteorological conditions (Sect. 2). The results of these simulations are then used to compute the bulk properties of the well-mixed layers that are equivalent to the bulk properties of the STBLs as represented by the LES. From these properties, we derive the bulk properties of the clouds that would develop in these well-mixed layers, and we compare them to the horizontally averaged properties of the clouds simulated at the same times. These comparisons will emphasize whether, while the bulk states of the well-mixed layers are correctly specified, the ML framework reproduces the differences between the pristine and the polluted clouds showed by the LES (Sect. 3). The next step consists in comparing the fluxes of heat and moisture at the boundaries of the equivalent well-mixed layers, computed within the ML framework, with the horizontal averages of the simulated fluxes. In order to quantify the impacts of the errors made by representing the different fluxes at the boundaries with the ML framework, we will discuss the errors that they would imply on the prediction of the difference in LWP between pristine and polluted clouds (Sect. 4). Finally, we use the ML theory to predict the evolutions of pristine/polluted STBLs and we compare the results with those obtained from LES (Sect. 5). Section 6 summarizes what we learned through the course of this exercise.

\section{Large-Eddy Simulations}

To explore a broad range of meteorological conditions three pairs of LES of the diurnal cycle of the STBL are performed. The external forcing is typical of Northeast Pacific summertime stratocumulus regime. The three pairs of simulations represent modified runs of the EUROCS/FIRE case (Duynkerke et al., 2004).

For each pair, a first simulation is ran for a duration of $75 \mathrm{~h}$, starting at 21:00 local time (LT), with a cloud condensation nuclei $(\mathrm{CCN})$ concentration typical of a pristine air mass, i.e. $50 \mathrm{~cm}^{-3}$, that results in CDNC values of about $40 \mathrm{~cm}^{-3}$. The same simulation is then replicated, but the $\mathrm{CCN}$ concentration is suddenly increased at midnight (i.e. after the spin-up period of $3 \mathrm{~h}$ ) to a value of $600 \mathrm{~cm}^{-3}$. The $\mathrm{CCN}$ activation scheme rapidly adjusts CDNC to this new $\mathrm{CCN}$ background, with CDNC values of about $200 \mathrm{~cm}^{-3}$. These two classes of simulations are hereafter referred to as PRIS and POL, respectively. The PRIS simulations always produce precipitation (Sect. 2.3.2), while the CDNC increase in the POL set of simulations is sufficient to inhibit drizzle formation within a few hours after the CCN concentration has been changed (Sect. 2.3.1). The first $12 \mathrm{~h}$ (from 00:00 to 12:00 LT on the first day of simulation) are disregarded in our subsequent 
analysis as we are not interested in the transient response to the sudden change in the CCN concentrations. The overall duration of each simulation, twice as long as in Sandu et al. (2008), was chosen in order to capture the effect of the timevarying boundary conditions and thereby provide a richer, hopefully somewhat more general, family of cases for study; particularly in light of past work that shows the planetary boundary layer (PBL) remembers its upstream environment for a day or more, e.g., Schubert et al., 1979; Klein and Norris, 1995; Pincus et al., 1997. Note also that concomitant impacts due to aerosol absorbing properties (the semi-direct effect) are disregarded by choosing a single scattering albedo typical of cloud droplets formed on sulphate, which has a low absorption coefficient, similar to that of pure water.

\subsection{The LES model}

The numerical model used in this study is the threedimensional LES configuration of the non-hydrostatic model Meso-NH (Lafore et al., 1998), described in detail in Sandu et al. (2008), which uses a grid mesh of $50 \mathrm{~m}$ on the horizontal and of $10 \mathrm{~m}$ on the vertical. This model solves a bulk microphysical representation of the cloud processes (using the parameterizations of Cohard et al. (2000a) for CCN activation, Khairoutdinov and Kogan (2000) for droplet autoconversion and accretion and for drizzle sedimentation, and Geoffroy (2007) for droplet sedimentation) and incorporates a detailed representation of radiative processes (Morcrette, 1991). The model uses a positive definite third order advection scheme based on a Piecewise Parabolic Method (Colella and Woodward, 1986) which advects the moist conservative variables, i.e. $\theta_{l}$ and $q_{t}$.

\subsection{Configuration}

The three pairs of simulations consist of one with constant sea surface temperatures (SST) and divergence, another with time-varying SSTs and fixed large-scale divergence, and a third with both the SSTs and the divergence varying in time. The last two pairs of simulations are thus performed in a Lagrangian framework. The latter perhaps most realistically represents the evolution of boundary layer air masses as they circumnavigate the summertime subtropical high-pressure zones. The base values of the SST and divergence are taken as $288 \mathrm{~K}$ and $6 \times 10^{-6} \mathrm{~s}^{-1}$, respectively. When allowed to vary SST is increased at a rate of $1.5 \mathrm{~K} \mathrm{day}^{-1}$ and divergence is decreased by $1 \times 10^{-6} \mathrm{~s}^{-1}$ day $^{-1}$, both changes being consistent with previous climatologies (Neiburger, 1960; Klein and Hartmann, 1993; Klein and Norris, 1995; Pincus et al., 1997). The model setup and the initial conditions for the three pairs of simulations are summarized in Table 1, while the resulting STBL bulk variables and flux values are reported in Table 2.

The initial data are taken from the EUROCS/FIRE case specification (Duynkerke et al., 2004), with some slight modifications. The initial profiles of $\theta_{l}$ and $q_{t}$ and the initial SST value are slightly modified so that the case with fixed boundary conditions behaves (in the pristine realization) quasi-periodically with a diurnal mean LWP of approximately $60-70 \mathrm{~g} \mathrm{~m}^{-2}$. This value is typical of marine stratocumulus over North-East Pacific during summertime (Wood et al., 2002). Furthermore, the free-tropospheric humidity was set to a constant value (cf Krueger et al., 1995) to avoid a temporal drift as the free-troposphere is allowed to gently subside (Table 1).

The large scale-subsidence which is specified by assuming a fixed divergence, $D$, within the boundary layer, and no divergence aloft, is the only forcing considered in our simulations. By continuity, $w_{s}=-D z$ for $z<z^{*}$ and $w_{s}=-D z^{*}$ for $z>z^{*}$, where $z^{*}=600 \mathrm{~m}$ was chosen because it is the initial STBL depth. The influence of the subsidence on the temperature and water content profiles is accounted for via the source terms $w_{s} \frac{\partial \theta_{l}}{\partial z}$ and $w_{s} \frac{\partial q_{t}}{\partial z}$ in the equations for $\theta_{l}$ and $q_{t}$. As mentioned above, the initial moisture data is chosen to avoid secular effects from subsidence in the free-troposphere. Because the radiation cooling does not exactly balance the subsidence warming secular effects are apparent in the potential temperature field. These effects range from 1 to $3 \mathrm{~K}$ depending on the boundary conditions, and are evident in Fig. 2a. Because these effects are not substantially affected by the state of the aerosol, they do not play a significant role in the differences between the pristine and polluted sets of simulations. Even so, the coupling of the large-scale forcing to the flow in our simulations is, in retrospect, not elegant and should be improved upon in future work. One possibility might be to specify subsidence using a local weak temperature gradient approach above the boundary layer, although such an approach might make it difficult to maintain continuity in $w_{s}$ at the top of the boundary layer.

\subsection{Description of the simulations}

\subsubsection{Polluted clouds}

The case with time-invariant forcing features a pronounced diurnal cycle, though with a progressive damping of the cycle amplitude and a decline of the daily mean LWP (Fig. 1a). Figure 2 reveals that over the $72 \mathrm{~h}$ of simulation both $\theta_{l}$ and $q_{t}$ do not change noticeably, although the height of the boundary layer slightly decreases with time.

Letting the SST increase with time leads to stronger surface fluxes (Fig. 1b) and the boundary layer progressively warms and moistens (Fig. 2). Increased surface heat and moisture fluxes also strengthen the buoyancy flux, and the entrainment velocity increases slightly in response (Table 3 ). Overall the warming of the STBL dominates the moistening and the lifting condensation level rises faster than the cloud top, thus the LWP therefore diminishes gradually (Fig. 1a). This case behaves similarly to the case of Wyant et al. (1997) which was forced similarly. 
Table 1. Characteristics of the simulations.

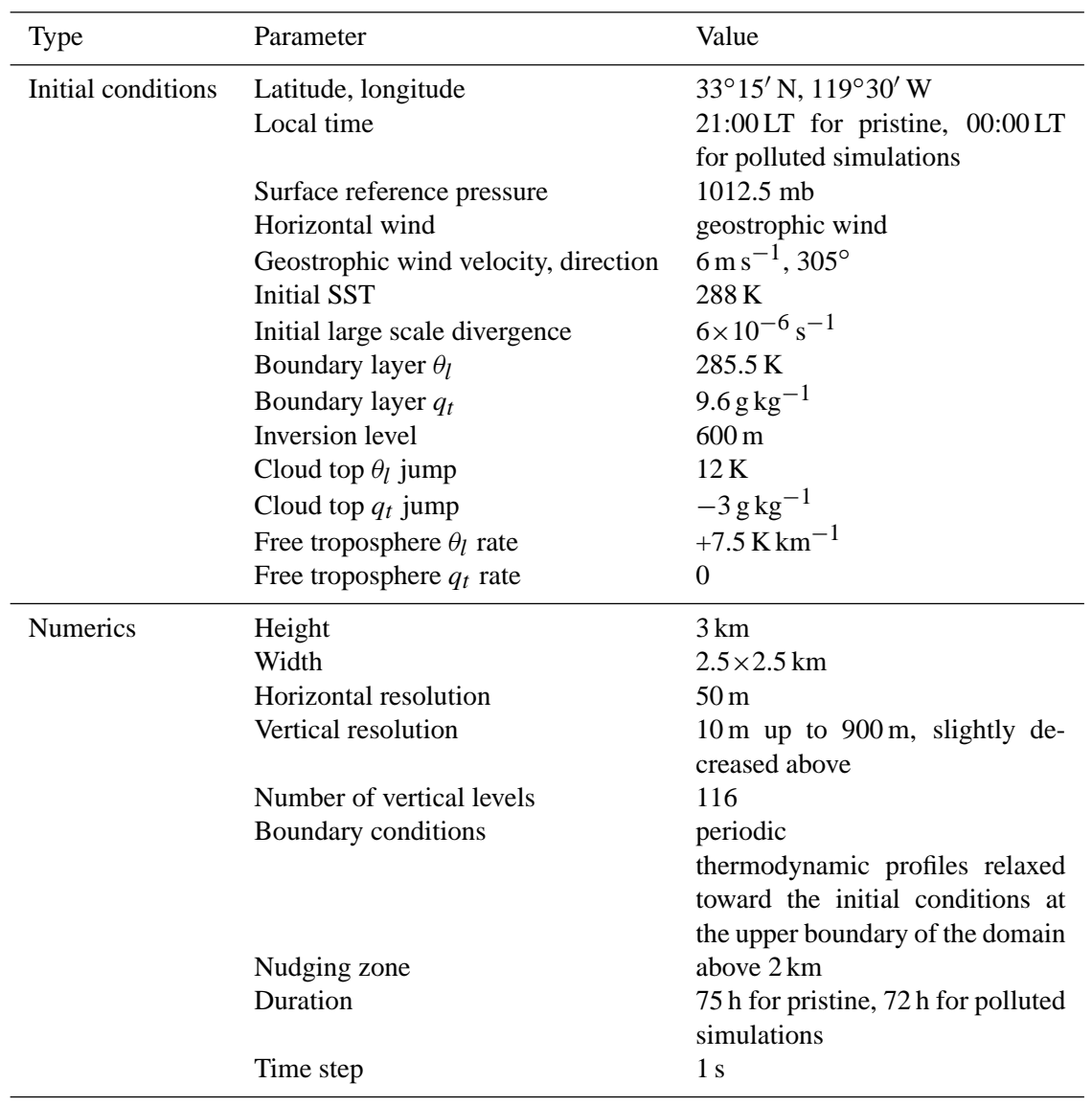

Table 2. Range of variation of the key variables in the simulations: mean $\theta_{l}$ and $q_{t}$ over the STBL, maximum LWC, $\theta_{l}, q_{t}$ and buoyancy jumps at cloud top, sensible and latent heat fluxes at the surface, upward net radiative flux jump at cloud top, cloud fraction (a column is considered as cloudy if the LWP is bigger than $2 \mathrm{~g} \mathrm{~m}^{-2}$ ), inversion level, SST, and large scale divergence.

\begin{tabular}{ll}
\hline Parameter & Range \\
\hline$\overline{\theta_{l}}(\mathrm{~K})$ & {$[286,291.5]$} \\
$\overline{q_{t}}\left(\mathrm{~g} \mathrm{~kg}^{-1}\right)$ & {$[8.7,10.5]$} \\
$q_{l, \max }\left(\mathrm{g} \mathrm{kg}^{-1}\right)$ & {$[0.14,0.53]$} \\
$\Delta \theta_{l}(\mathrm{~K})$ & {$[8.5,11]$} \\
$\Delta q_{t}\left(\mathrm{~g} \mathrm{~kg}^{-1}\right)$ & {$[-4,-2]$} \\
$\Delta b\left(\mathrm{~m}^{2} \mathrm{~s}^{-3}\right)$ & {$[0.24,0.32]$} \\
$\overline{w^{\prime} \theta_{l}^{\prime}}(0)\left(\mathrm{W} \mathrm{m}^{-2}\right)$ & {$[-3,8.5]$} \\
$\overline{w^{\prime} q_{t}^{\prime}}(0)\left(\mathrm{W} \mathrm{m}^{-2}\right)$ & {$[10.7,54.3]$} \\
$\left.\Delta F(\mathrm{~W} \mathrm{~m})^{-2}\right)$ & {$[26,66.4]$} \\
cloud fraction & {$[0.85,1]$} \\
inversion level $(\mathrm{m})$ & {$[600,1000]$} \\
SST $(\mathrm{K})$ & {$[288,292.5]$} \\
LS divergence $\left(\mathrm{s}^{-1}\right)$ & {$\left[3 \times 10^{-6}, 6 \times 10^{-6}\right]$} \\
\hline
\end{tabular}

In the case when the divergence is also allowed to gradually weaken with time, the growth of the boundary layer is (as expected) even more pronounced through the course of the simulation (Fig. 2). The thermodynamic state of the STBL largely follows the same evolution as in the case with only time-varying SSTs, but given that the STBL is deeper the cloud thickens relative to the previously described case (Fig. 1a). The most significant difference arising from the progressive weakening of the subsidence is the development of larger differentiation between the cloud and subcloud layer total-water specific humidity, which appears to be associated with the tendency of the more rapidly deepening layer to more strongly decouple (Fig. 2), and entrain somewhat more rapidly (e.g., Table 3 ). The reason for it to entrain more rapidly is unclear, but may be related to a thicker cloud layer.

Figure 3 provides information about the buoyancy fluxes for the three cases (grey points for the non-precipitating cases). The information is summarized in the decoupling parameter that is defined as the ratio of the negative to the positive areas of the buoyancy flux vertical profile in the boundary layer, i.e., the Buoyancy Integral Ratio, (Turton and Nicholls, 1987; Bretherton and Wyant, 1997; Stevens, 2000a). High values of this parameter indicate 
Table 3. Diurnal mean LWP $\left(\mathrm{g} \mathrm{m}^{-2}\right)$, amplitude of the LWP diurnal cycle $(\mathrm{A})\left(\mathrm{g} \mathrm{m}^{-2}\right)$ and diurnal mean entrainment rate $w_{e}\left(\mathrm{~cm} \mathrm{~s}^{-1}\right)$ for each day of simulation in the three scenarios, for polluted and pristine clouds.

\begin{tabular}{|c|c|c|c|c|c|c|c|c|c|c|}
\hline \multirow[t]{2}{*}{ Parameter } & \multirow[t]{2}{*}{ Sim. } & \multicolumn{3}{|c|}{ Fixed boundary conditions } & \multicolumn{3}{|c|}{ Time-varying SST } & \multicolumn{3}{|c|}{$\begin{array}{l}\text { Time-varying SST } \\
\text { and divergence }\end{array}$} \\
\hline & & Day 1 & Day 2 & Day 3 & Day 1 & Day 2 & Day 3 & Day 1 & Day 2 & Day 3 \\
\hline \multirow[t]{2}{*}{$\overline{\mathrm{LWP}}$} & POL & 65.7 & 53.3 & 51.7 & 64.4 & 39.7 & 26.4 & 67 & 55.1 & 53.9 \\
\hline & PRIS & 65.2 & 66.7 & 64.3 & 61.4 & 45.2 & 26.1 & 64.2 & 59.1 & 61.8 \\
\hline \multirow[t]{2}{*}{ A } & POL & 87 & 52.4 & 46.9 & 80.6 & 38.5 & 28.2 & 78.5 & 52.4 & 79.7 \\
\hline & PRIS & 44.3 & 43.4 & 42.5 & 49.6 & 44.3 & 31.8 & 40.6 & 43.7 & 46.1 \\
\hline \multirow[t]{2}{*}{$w_{e}$} & POL & 0.32 & 0.29 & 0.26 & 0.37 & 0.38 & 0.38 & 0.38 & 0.42 & 0.47 \\
\hline & PRIS & 0.24 & 0.23 & 0.21 & 0.28 & 0.34 & 0.34 & 0.3 & 0.37 & 0.44 \\
\hline
\end{tabular}
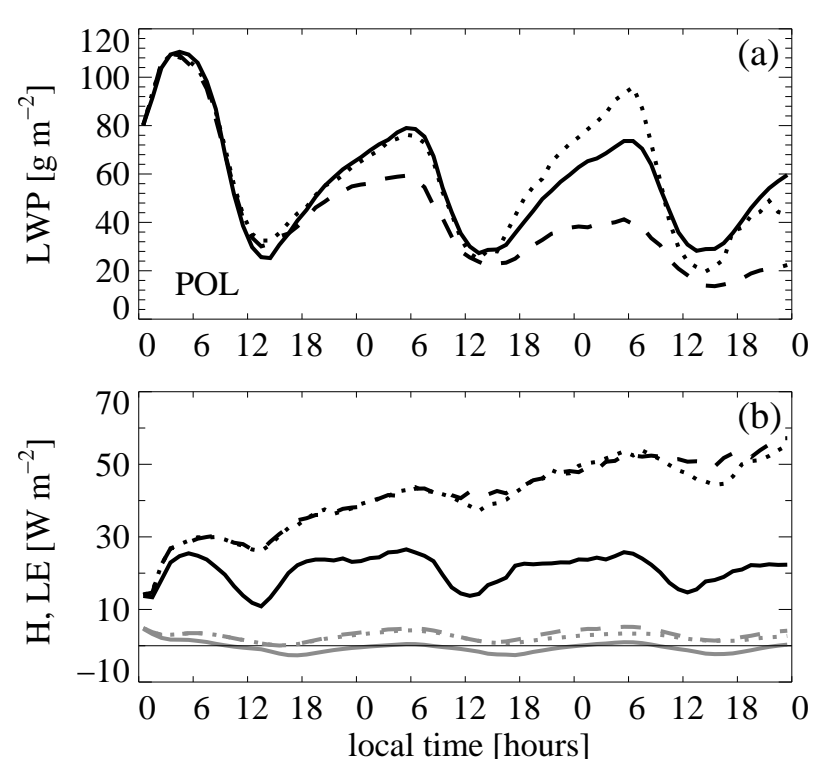

Fig. 1. Time evolution of the horizontal mean: (a) LWP $\left(\mathrm{g} \mathrm{m}^{-2}\right)$ and (b) sensible (grey lines) and latent heat (black lines) fluxes at the surface $\left(\mathrm{W} \mathrm{m}^{-2}\right)$ for the polluted STBLs simulated in the cases: with fixed boundary conditions (full), with time-varying SSTs (dashed) and with time-varying SSTs and divergence (dotted).

that turbulence forced by surface or radiative fluxes is increasingly dissipated in its effort to maintain a well-mixed layer. Both the case with fixed boundary conditions and the case with time-varying SSTs and divergence exhibit a significant decoupling during the day (from 10:00 to 16:00 LT). In contrast, the decoupling in the case where only the SSTs vary in time is less pronounced and almost disappears after $60 \mathrm{~h}$ of simulation. This feature corroborates previous work (Bougeault, 1985; Bretherton and Wyant, 1997) showing that deeper STBLs are often more decoupled, but it also reveals that decoupling is not a necessary condition for a decrease of the LWP.
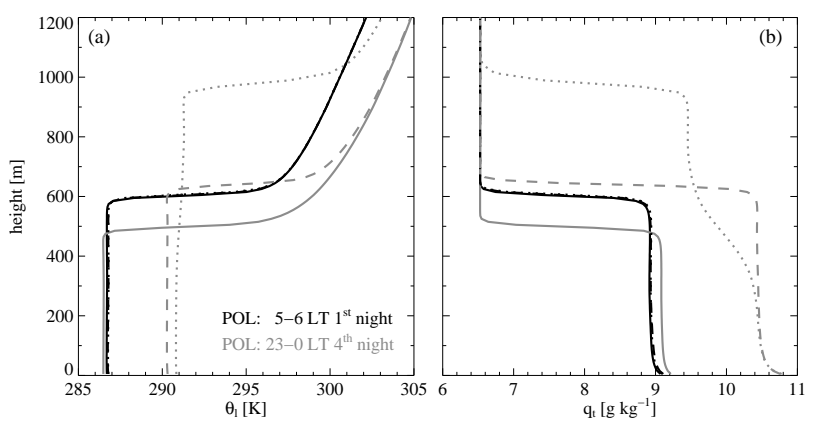

Fig. 2. Vertical profiles of the horizontal mean (a) liquid water potential temperature $(\mathrm{K})$ and $(\mathbf{b})$ total water mixing ratio $\left(\mathrm{g} \mathrm{kg}^{-1}\right)$, averaged from 05:00 to 06:00 LT during the 1st night (black) and from 23:00 to 00:00 LT during the last night of simulation (grey). The full, dashed and dotted lines correspond to the polluted STBL simulated in cases with fixed boundary conditions, with timevarying SSTs and with time-varying SSTs and divergence, respectively.

\subsubsection{Precipitating clouds}

At first glimpse, the precipitating cases behave like the nonprecipitating ones (Table 3): the case with fixed forcing develops a slowly shallowing boundary layer, while the boundary layer top in the other simulations progressively increases albeit not as rapidly as in the cases with a polluted aerosol. The LWP evolves similarly among the three cases as before. Note, however, that because of its decreasing LWP, the precipitation in the SST case is inhibited during the third day of simulation (Fig. 4b).

Systematic, or robust differences between pairs of precipitating and non-precipitating representations of a particular scenario are evident in the daily mean LWP value and the amplitude of the LWP diurnal variation (Table 3). The mean LWP values are higher and the amplitude of the diurnal cycles are lower in the precipitating simulations, compared to the non-precipitating ones, on days 2 and 3, an exception being the last day of the case with only time-varying SSTs. 

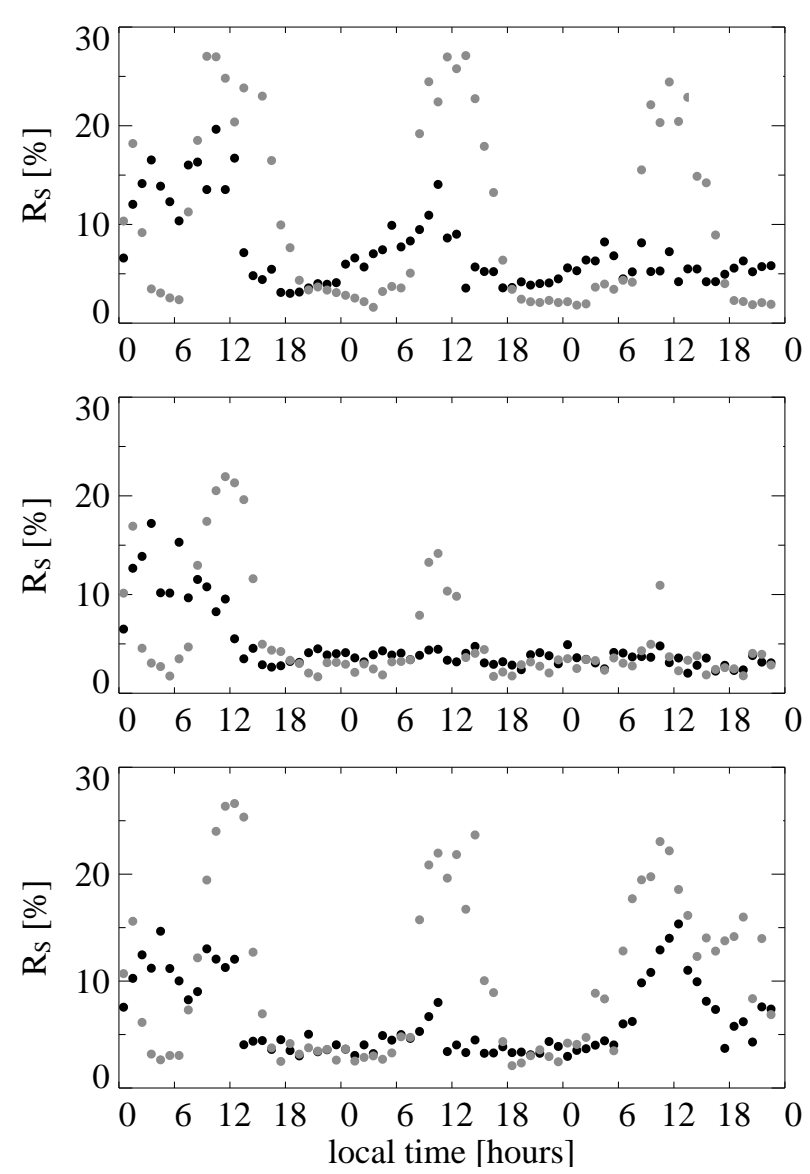

Fig. 3. Time evolution of the hourly averaged decoupling criterion $R_{S}(\%)$ for the pristine (black) and polluted STBLs (grey). The upper, middle and lower panels correspond to the cases with fixed boundary conditions, with time-varying SSTs and with timevarying SSTs and divergence, respectively.

The first day is disregarded because of the spin-up period that follows the sudden increase of CDNC at 00:00 LT. As mentioned above, day 3 for the case with time-varying SST shows a different response because precipitation is no longer active.

This contrasting features of the precipitating versus nonprecipitating STBLs were discussed in Sandu et al. (2008). When drizzle is efficient the boundary layer does not entrain as much (Table 3), and tends to remain shallow and moist, if anything decoupling during the night due to the evaporation of precipitation below cloud base (Fig. 3). In the day a weak drizzle flux continues to contribute to less entrainment and evaporates near cloud base, counteracting the tendency of the layer to diurnally decouple. The precipitating STBLs are thus less decoupled during the daytime hours than the non-precipitating ones (Fig. 3). Thus, as long as the cloud precipitates, the diurnal cycle of the STBL is reduced, and its LWP is reinforced (Fig. 4a), compared to a non-precipitating
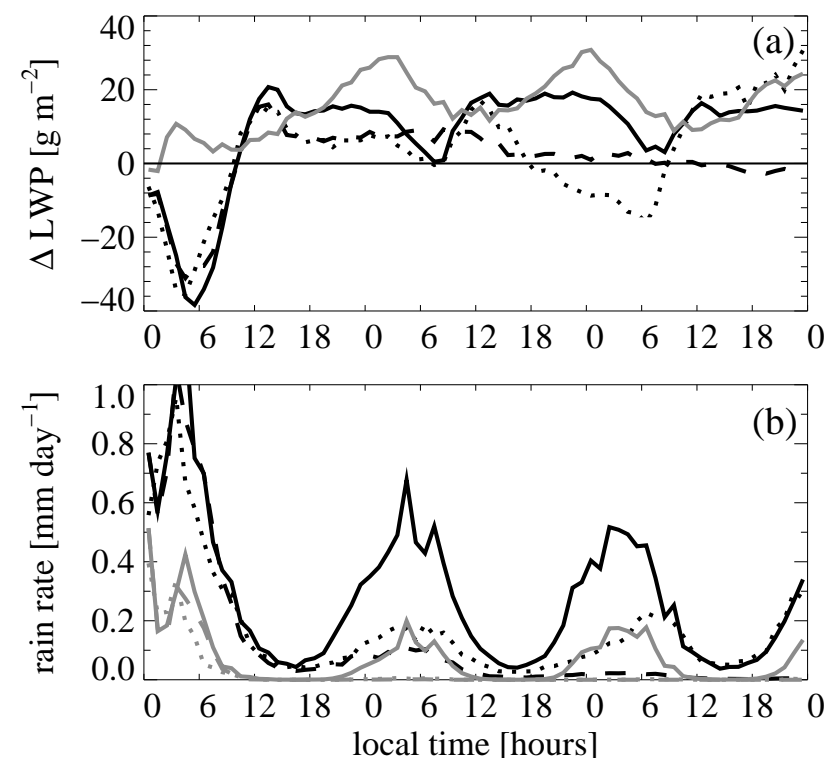

Fig. 4. Time evolution of (a) the difference in horizontal mean LWP $\left(\mathrm{g} \mathrm{m}^{-2}\right)$ between the pristine and the polluted clouds and (b) the precipitation rates $\left(\mathrm{mm} \mathrm{day}^{-1}\right)$ at sea level (grey) and at cloud base (black) for the pristine clouds simulated in the cases with fixed boundary conditions (full), with time-varying SSTs (dashed) and with time-varying SSTs and divergence (dotted), respectively. The full grey line in panel (a) shows the difference between the LWPs of the well-mixed layers equivalent to the pristine and polluted STBLs simulated in the case with fixed boundary conditions.

STBL exposed to the same external forcing. These features are evident to some degree in each pair of simulations in Fig. 3, and thus this basic mechanism does not appear sensitive to the details of the state of the STBL.

In summary, an aerosol indirect effect has been simulated, where increased CCN enhances CDNC and inhibits drizzle precipitation in the STBL. In these simulations, droplet and drizzle sedimentation appears to be important at two levels: at cloud top where it attenuates the entrainment of free tropospheric air, and below cloud base where it modulates the degree of decoupling of the STBL and thus moderates the amplitude of the diurnal cycle and hence affects the cloud albedo. Because such effects would seem to be dependent on the vertical coupling of the STBL it is interesting to ask how well a model that does not well represent this coupling is able to capture the differences between pristine and polluted clouds. In other words, how important is it for large-scale models to accurately represent the evolution of the STBL vertical structure if they are to be expected to capture the effects of the aerosol on cloud amount. 


\section{Vertical structure and cloud bulk properties}

To begin we first investigate whether the difference in LWP between a pristine and a polluted cloud represented by LES can be captured without incorporating information about the vertical structure. We recall that in the simplest 0-D cloudy boundary layer model, i.e. the mixed-layer model, the conservative variables, $\theta_{l}$ and $q_{t}$, are by definition constant with altitude through the depth of the boundary layer. To compare the LWP that would have been produced had the simulations remained well-mixed with the results of the 3-D simulations, we construct what we call an equivalent mixed-layer (EML). That is a vertically uniform (in $\theta_{l}$ and $q_{t}$ ) column, with the same depth as the mean 3-D STBL, the same mass of dry air and of water, hence same moist static energy. The EML is calculated for the entire set of simulations, at intervals of $10 \mathrm{~min}$. Once $\theta_{l}$ and $q_{t}$ have been defined it is then possible to derive the EML cloud base and LWP, and to compare them with the mean 3-D LES ones.

Figure 5 compares the mean LWP of the LES simulations to the LWP of the EMLs, for the entire set of simulations, from 12:00 LT on the first day to the end of the simulations. Each point represents an hourly mean of the respective quantities. This figure suggests that the EML often provides a satisfactory diagnostic of the LWP. Some values, however, are significantly overestimated, especially for the periods when the polluted or the pristine simulated STBLs are decoupled (grey and black stars). The EML never underestimates the amount of liquid water as deviations from a well-mixed state are always such that they tend to raise the condensation level, and therefore thin the cloud. In fact, the overestimation of the LWP in the EML is expected since in the STBL the moisture from the surface accumulates at the lowest levels, while dry air is entrained at cloud top. Turbulent mixing then partially neutralizes this moisture gradient. Since the same amount of total water is by definition uniformly distributed throughout the vertical in the EML, this layer is moister than its mean LES counterpart in the upper part of the STBL, and its LWP is overestimated. When the STBL is decoupled, turbulent mixing is less efficient, the moisture gradient in the LES simulation is less efficiently neutralized, and the discrepancy with the EML is more pronounced (Fig. 5).

The real question is however, whether or not the mixedlayer assumption can capture the sensitivity of the liquid water path to the aerosol, as simulated by the LES. As a first step in answering this question the EML LWP difference between the PRIS and POL simulations, for the case with fixed forcing, is superimposed in Fig. 4a. This set of simulations presents the most marked differences between the precipitating and the non-precipitating clouds. The figure reveals that the ML assumption slightly underestimates the LWP difference during the day, more specifically from 10:00 to 16:00 LT, while it significantly overestimates it at nighttime and in the early morning. These time periods also correspond to contrasting values of the decoupling criterion, between

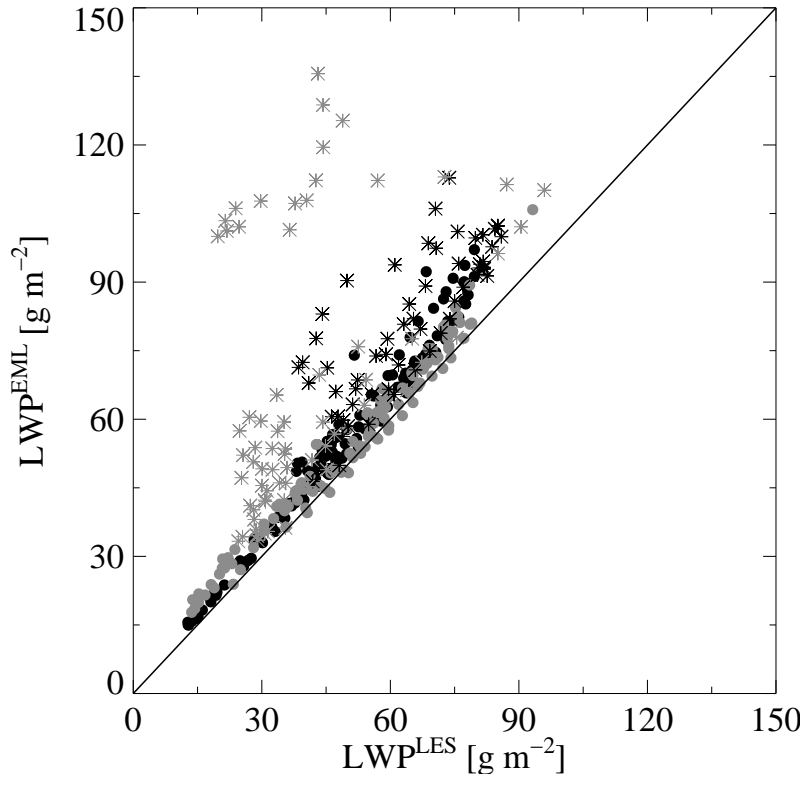

Fig. 5. EML LWP against the LES LWP $\left(\mathrm{g} \mathrm{m}^{-2}\right)$. The black and grey symbols correspond to pristine and polluted cases, respectively. The dots and stars represent situations when the STBL is well-mixed and decoupled, respectively. A STBL is considered to be decoupled if $R_{S}>5 \%$.

the PRIS and POL simulations (Fig. 3). The discrepancy in the diagnosis of the LWP difference is less noticeable during daytime because, in both simulations, the LWP is significantly reduced compared to nighttime.

The overall impact is shown in Fig. 6, where the LWP difference between PRIS and POL EML calculations is plotted against the one of the LES for the three pairs of simulations. It appears (as expected) that when both STBLs are wellmixed (black dots), the EML reproduces the sign of the difference in LWP between the pristine and the polluted cloud. Meanwhile, this difference is noticeably overestimated during the nighttime periods when the pristine STBL is decoupled while the polluted one is well-mixed (green stars). During the periods when the polluted STBL only (orange stars) or both STBLs (red stars) are decoupled, which mostly correspond to daytime conditions, the difference in LWP between the two clouds is underestimated, and in some cases it is even reversed. The largest discrepancies (lower-right corner in Fig. 6) correspond to the last day of simulation with timevarying SST and divergence, for which Fig. 3 (lower panel) reveals that both the PRIS and POL simulations are significantly decoupled. It appears thus, that in the cases when at least one of the two STBLs is decoupled, the mixed-layer framework may fail to reproduce the difference in LWP between pristine and the polluted clouds. The errors arise from a failure to incorporate the effects of decoupling. Because this decoupling occurs during different parts of the diurnal 


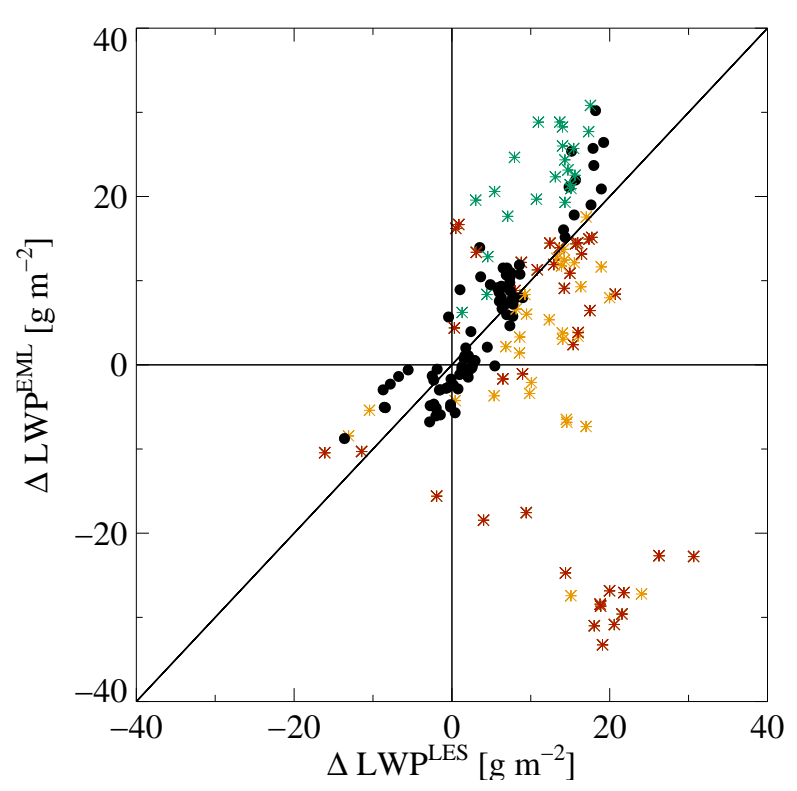

Fig. 6. Difference between the EML pristine and polluted LWPs against the difference between the LES ones $\left(\mathrm{g} \mathrm{m}^{-2}\right)$. The black dots correspond to situations when both STBLs are well-mixed, while the stars correspond to cases when: only the pristine STBL is decoupled (green), only the polluted STBL is decoupled (orange), both STBLs are decoupled (red).

cycle, and with differing amplitudes, for pristine versus polluted clouds, errors arising from a failure to account for such effects do not offset each other.

\section{Vertical structure and fluxes at the interfaces}

A second question, is whether or not a model that fails to account for the structure of thermodynamic variables within the layer (i.e., a mixed-layer model - MLM) might be expected to properly predict the evolution of the difference in LWP between a pristine and a polluted cloud, despite of the fact that it does not capture the differences in vertical structure between the two STBLs.

To answer this we first need to understand how sensitive the boundary fluxes, including the surface, entrainment and radiative fluxes, of the ML are to the assumed vertical structure. Indeed, the divergence of these fluxes controls the evolution of the mixed-layer bulk state as follows:

$\left(\frac{d \phi}{d t}\right)_{\mathrm{ML}}=-\frac{\overline{w^{\prime} \phi^{\prime}}\left(z_{i}\right)-\overline{w^{\prime} \phi^{\prime}}(0)}{z_{i}-z(0)}$,

where $\phi=\left\{\theta_{l}, q_{t}\right\}$. The fluxes at the boundaries: $\overline{w^{\prime} \phi^{\prime}}\left(z_{i}\right)$ and $\overline{w^{\prime} \phi^{\prime}}(0)$, at the inversion level $z_{i}$ and at the surface, respectively are given by:

$$
\begin{aligned}
& \overline{w^{\prime} \theta_{l}^{\prime}}\left(z_{i}\right)=-w_{e} \Delta \theta_{l}+\frac{\Delta F_{R}}{\rho_{l} C_{p d}}, \\
& \overline{w^{\prime} \theta_{l}^{\prime}}(0)=H+L_{v} / C_{p d} F_{p}(0), \\
& \overline{w^{\prime} q_{t}^{\prime}}\left(z_{i}\right)=-w_{e} \Delta q_{t}, \\
& \overline{w^{\prime} q_{t^{\prime}}}(0)=L E+F_{p}(0),
\end{aligned}
$$

where $w_{e}$ is the entrainment rate, $\Delta \theta_{l}$ and $\Delta q_{t}$ are the jumps in $\theta_{l}$ and $q_{t}$ at the inversion, $\mathrm{H}$ and LE are the sensible and latent heat fluxes at the surface, $F_{p}(0)$ is the precipitation flux at the surface $(<0), L_{v}$ is the enthalpy of vaporisation, $C_{p d}$ is the isobaric specific heat capacity of dry air and $\Delta F_{R}$ is the divergence of the upward net radiative flux across the mixed-layer.

In what follows we will therefore explain how the fluxes at the boundaries of the EMLs are computed, and which are the sources of errors inherent to the ML assumption. Then, we will discuss the errors on the prediction of the LWP induced by using the EMLs fluxes instead of those of the mean 3D STBL. Finally, we will get back to the central question of how these errors impact our ability to predict differences in the evolution of the LWP between pristine and polluted clouds.

\subsection{Flux calculation in the EML}

\subsubsection{Surface fluxes}

The surface sensible and latent heat fluxes are proportional to the differences in $\theta_{l}$ and $q_{t}$ between the ocean surface and the atmosphere just above. They are derived using the same formulation as in the LES simulations, except for the $\theta_{l}$ and $q_{t}$ values at the bottom of the column that are those of the EML.

In a first time we consider that there is no precipitation in the EMLs, which signifies that the precipitation flux at the surface $\left(F_{p}(0)\right)$ in Eq. ( $2 \mathrm{~b}$ and d) is equal to zero. In Sect. 4.3 we will discuss a test where we include a diagnostic precipitation flux at the surface in the EMLs.

\subsubsection{Radiative fluxes}

The vertical profiles of the radiative fluxes within the EML are computed with an off-line version of the radiative transfer code of Meso-NH, assuming that the cloud optical properties (asymmetry factor and single scattering albedo) are the same in the polluted and pristine sets of simulations (no semidirect aerosol effect). For these computations two additional assumptions are made. First, we specify that above the wellmixed layer the properties of the atmosphere are identical to those of the mean LES column simulated at that time. Second, the CDNC is kept constant from the cloud base to the top and equal to the CDNC value simulated at that time, averaged over LES model grid cells where it is greater than $20 \mathrm{~cm}^{-3}$. The calculated profiles of the radiative fluxes are 
Table 4. Overall bias and correlation coefficients for the entrainment rates over the entire set of simulations, and relative error for the pristine and polluted cases respectively.

\begin{tabular}{lrrrr}
\hline Parameterization & Bias $\left(\mathrm{cm} \mathrm{s}^{-1}\right)$ & Correlation & \multicolumn{2}{c}{ Rel. error (\%) } \\
& & & POL & PRIS \\
\hline Turton and Nicholls (1987) & -0.013 & 0.827 & -13 & 8 \\
Lock (1998) & -0.099 & 0.737 & -35 & -22 \\
Konor and Arakawa (2001) & 0.984 & 0.634 & 255 & 355 \\
Moeng (2000) & 0.062 & 0.765 & 12 & 33 \\
Lilly (2002) & -0.089 & 0.897 & -32 & -20 \\
Lilly and Stevens (2008) & -0.1 & 0.882 & -32 & -24 \\
Bretherton et al. (2007) & -0.2 & 0.93 & -58 & -63 \\
\hline
\end{tabular}

then used to derive the divergence of the upward net radiative flux across the boundary layer (solar plus infrared), taken as the difference between the value of the upward net flux above the EML and its value at the surface.

\subsubsection{Fluxes at the boundary layer top and entrainment rate}

The heat and moisture fluxes at the boundary layer top are derived following Eq. (2), where the values above the EML, for the specification of the $\theta_{l}$ and $q_{t}$ jumps through the inversion, are taken from the mean values of the LES.

For the entrainment rate, several parameterizations (Turton and Nicholls, 1987; Konor and Arakawa, 2001; Lock, 1998; Moeng, 2000; Lilly, 2002; Lilly and Stevens, 2008) are tested, some of them including the liquid water sedimentation effect on cloud top entrainment (Bretherton et al., 2007). An evaluation of their results is summarized in Table 4. They have all been formulated following the ML theory outlined in Stevens (2002). These parameterizations were initially developed for nocturnal conditions (no solar radiation). For application to the diurnal cycle, we therefore consider that the divergence of the radiative flux across the boundary layer top is equal to the divergence of the net upward total (solar plus thermal infrared) radiative flux (i.e. the difference between the value of the upward net flux above the inversion and its minimum value within the boundary layer).

For evaluation, the parameterized entrainment rates are computed from the horizontally averaged LES values of surface fluxes, radiative divergence at cloud top, which includes both solar and infrared fluxes, and jumps in $\theta_{l}$ and $q_{t}$ at cloud top. Over the entire set of PRIS and POL simulations they show relatively high correlation coefficients and small biases (except for the Konor and Arakawa (2001); Bretherton et al. (2007) parameterizations) (Table 4). If the correlation coefficients and the biases are computed for well-mixed cases only $\left(R_{S}<5 \%\right)$, the correlation coefficients become slightly better, but the biases slightly increase in the majority of cases (not shown). This suggests that the performances of the parameterizations over the entire set of cases are not artificially degraded in a significant way due to the fact that a part of the situations were decoupled, while originally these parameterizations were designed for well-mixed boundary layers.

The Turton and Nicholls (1987) parameterization has the smallest bias, a high correlation, and the smallest relative errors for both pristine and polluted cases, although it fails to reproduce correctly the difference in entrainment rates between pristine and polluted clouds (i.e. the averaged relative difference in entrainment rates between pristine and polluted clouds is of $-16 \%$ in the LES and of $+2 \%$ with the Turton and Nicholls (1987) parameterization). Keeping this caveat in mind (as it will become important later) our further evaluation of the mixed-layer theory is developed based on the Turton and Nicholls (1987) parameterization. It might be surprising that parameterizations that explicitly include a sedimentation effect did not better match our simulations. However, initial estimates of sedimentation effects on entrainment tended to exaggerate this effect by assuming an unrealistically broad droplet spectrum. Moreover sedimentation effects are implicitly captured by many of the parameterizations as they help determine the buoyancy and liquid water flux profiles which the parameterizations use as input.

\subsection{Process-wise impacts of the mixed-layer assumptions}

\subsubsection{Surface fluxes}

When the simulated STBL is decoupled, the subcloud layer is colder and moister than the cloud layer, so that the EML $\theta_{l}$ and $q_{t}$ values are therefore greater, and respectively smaller than the horizontally averaged LES $\theta_{l}$ and $q_{t}$ values at the surface. The surface sensible heat flux of the EML is therefore slightly weaker than the LES one, while the surface moisture flux is stronger.

\subsubsection{Radiative fluxes}

The discrepancies in the radiative fluxes between the EMLs and the LES simulations accumulate three sources of errors. First, it has been shown in the previous section that the LWP 

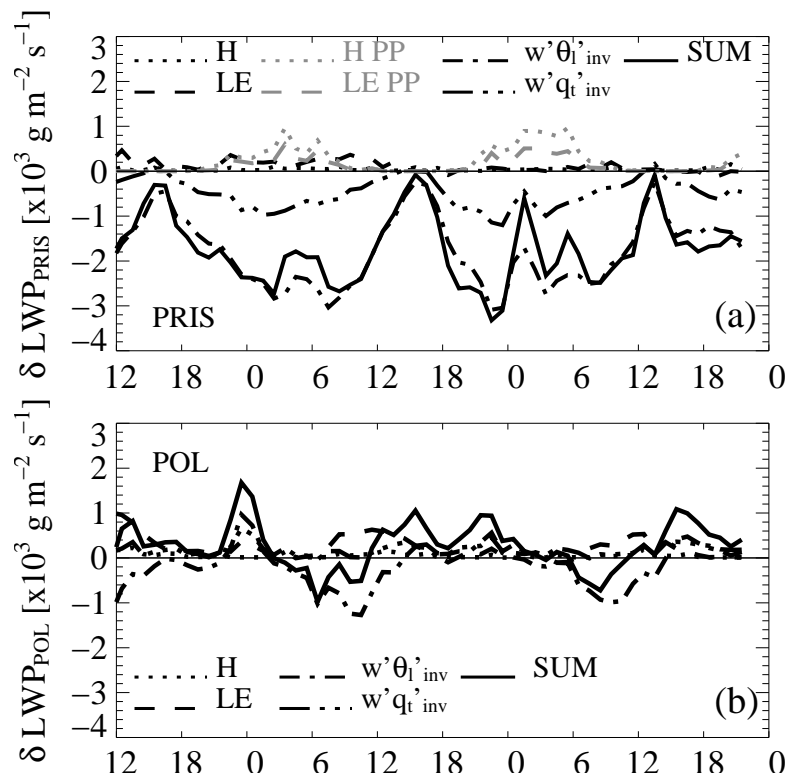

Fig. 7. Errors on the prediction of the LWP $\left(\mathrm{g} \mathrm{m}^{-2} \mathrm{~s}^{-1}\right)$ tendency when using the ML assumption to compute the various fluxes at the boundaries, as listed in the legend, of (a) a pristine and (b) a polluted STBL, and the total error (full line) (for the case with fixed boundary conditions).

is generally overestimated by the EML, especially when the STBL is decoupled. The corresponding flux divergence is accordingly overestimated. Second, the liquid water content (LWC) vertical profile is adiabatic by definition in the EML, with its maximum value at cloud top, while the mean LES LWC profiles exhibit a slightly lower maximum due to entrainment of dry air through the inversion layer. When precipitation is active, droplet and drizzle sedimentation tend to further lower the level of the LWC maximum (Sandu et al., 2008). Third, the mean radiative flux divergence of the LES is generally smaller than the flux divergence calculated with the mean LES fields (up to $5 \mathrm{~W} \mathrm{~m}^{-2}$ ) because radiative transfer is non linear and the LWP is heterogeneous horizontally (heterogeneous radiative bias, Barker and Davies, 1992). The same underestimation of the flux divergence thus appears in the EML, which is derived from the mean LES fields, and it tends to (at least partially) outweigh the overestimation of the flux divergence associated with the LWP overestimation in the EML. The errors on the flux divergence further lead to errors on the heat flux at the top of the STBL (Eq. 2a), and hence to errors on prediction of the STBL evolution.

\subsubsection{Entrainment rate}

The diagnosis of the entrainment rate is the most sensitive step in boundary layer models because it involves the energy fluxes at both the lower and upper interfaces, as well as the radiative fluxes to predict the generation of turbulent kinetic energy and the entrainment velocity. Noticeable discrepancies in the jumps of the conservative variables $\theta_{l}$ and $q_{t}$ across the inversion, between the LES and the EML also contribute to errors on the entrainment rates, especially when the STBL is decoupled, or heavily precipitating.

When the entrainment rate is computed using the surface fluxes, the radiative divergence at cloud top and the bulk properties of the EML instead of those of the mean LES column, the results obtained with Turton and Nicholls (1987) parameterization somewhat degrade, as expected, but the changes are not large.

\subsection{Effects on the prediction of the difference in LWP between pristine and polluted clouds}

To measure the impact of the vertical structure on the prediction of the LWP, we evaluate here the errors in the LWP tendency (expressed in $\mathrm{g} \mathrm{m}^{-2} \mathrm{~s}^{-1}$ ) that are introduced by using the fluxes at the boundaries of the EMLs instead of those at the boundaries of the mean 3-D STBLs.

The errors on the heat and moisture fluxes at the boundaries, when using the ML assumption, result in errors on the heating $\left(\delta\left(\frac{d \theta_{l}}{d t}\right)\right)$, and moistening $\left(\delta\left(\frac{d q_{t}}{d t}\right)\right)$ rates (not shown), hence in errors on the LWP tendency. The fluxes to consider are the surface sensible heat flux $(\mathrm{H})$, the surface latent heat flux (LE), the surface precipitation heat flux (H PP, i.e., the rightmost term in the right hand side of Eq. 2b), the surface precipitation latent heat flux (LE PP, i.e., the rightmost term in the right hand side of Eq. 2d), the inversion heat $\left.\overline{\left(w^{\prime} \theta_{l}^{\prime}\right.}\left(z_{i}\right)\right)$ and moisture $\left(\overline{w^{\prime} q_{t}^{\prime}}\left(z_{i}\right)\right)$ fluxes. To separate their respective contributions, the error on the LWP tendency is calculated for each flux separately, as the LWP change induced by either $\left.\delta\left(\frac{d \theta_{l}}{d t}\right)\right|_{q_{t}}$ or $\left.\delta\left(\frac{d q_{t}}{d t}\right)\right|_{\theta_{l}}$.

Figure $7 \mathrm{a}$ and $\mathrm{b}$ summarizes all the sources of errors for the pristine and the polluted simulations of the case with fixed boundary conditions with the contributions of each flux and the total error. It appears that the total error (i.e., the sum of the different errors) is bigger in the pristine case (Fig. 7a), due mainly to larger errors on the turbulent fluxes at the boundary layer top, i.e. larger errors on the entrainment rates (Sect. 4.1.3). Furthermore, the errors appear to be somewhat larger at night, when drizzle is effective in decoupling the boundary layer as represented by the LES. In the polluted case, the errors associated to each flux are smaller and they largely counterbalance one another, so that the total error on the LWP tendency is mostly smaller (Fig. 7b), albeit of opposite sign. This changing of sign may impact the sensitivity of the mixed-layer model to the character of the aerosol.

As noted in Sect. 4.1.1. for the computations performed so far we considered that there is no precipitation in the EMLs. The errors shown in the Fig. 7a for the precipitation flux thus correspond to the LES contribution alone (or otherwise said to the lack of precipitation in the EMLs). In an attempt to also include a diagnostic of the precipitation flux at the surface in 
the MLM, we use an empirical parameterization similar to the one proposed by Geoffroy et al. (2008) for the precipitation flux at cloud base, but based on an empirical fit to the values of the precipitation flux at the surface from our simulations. The total error on the LWP tendency is not improved and even increases (not shown). This is due to the overestimation of the LWP in the EML, that has been shown to be mostly noticeable when the STBL is decoupled. In the precipitating case, this LWP overestimation results in an overestimation of the precipitation flux at the surface.

These results show that the errors on the LWP tendency made in pristine and polluted cases do not have the same sign, nor the same magnitude, and therefore suggest that a noticeable error will be made on the prediction of the difference in LWP between two such clouds if the ML theory is used to compute the fluxes at the boundaries. Moreover, one observes that the ML assumption underestimates the LWP tendency when the cloud layer is precipitating. That bias might counterbalance the tendency of the ML framework to overestimate the LWP when the boundary layer is decoupled, as discussed in the previous section. To test such a hypothesis, we now let the MLM evolve freely, based on its own parameterizations.

\section{Performance evaluation of the MLM}

\subsection{Methodology}

For both the pristine and the polluted case, the MLM is initialized with the EML derived at 12:00 LT on the first day of simulation (for each of the three pairs of simulations). Its evolution is then computed, with a time step of $10 \mathrm{~min}$, using Eqs. (1) and (2), with the Turton and Nicholls (1987) parameterization for the entrainment rate. At each time step, the fluxes at the boundaries (computed as indicated in Sect. 4.1) are thus used to derive the heating and the moistening rates of the mixed-layer and the evolution of the conservative variables. In the meantime, the rate of growth of the mixed-layer is computed as the difference between the entrainment rate and the subsidence rate (equal to that imposed in the LES at that time). The bulk properties are then used to diagnose the LWP.

For the pristine cases, two such integrations are performed. In the first one, the precipitation is not parameterized, while in the second, we use the same empirical parameterization of the precipitation flux at the surface as described above.

\subsection{Results}

Figure 8a shows the time evolution of the difference in LWP between the PRIS and the POL LES performed in the case with fixed boundary conditions (full line) and the difference in LWP obtained from the integrations of the MLM, with (dotted) and without (dashed) precipitation at the surface in the PRIS case.
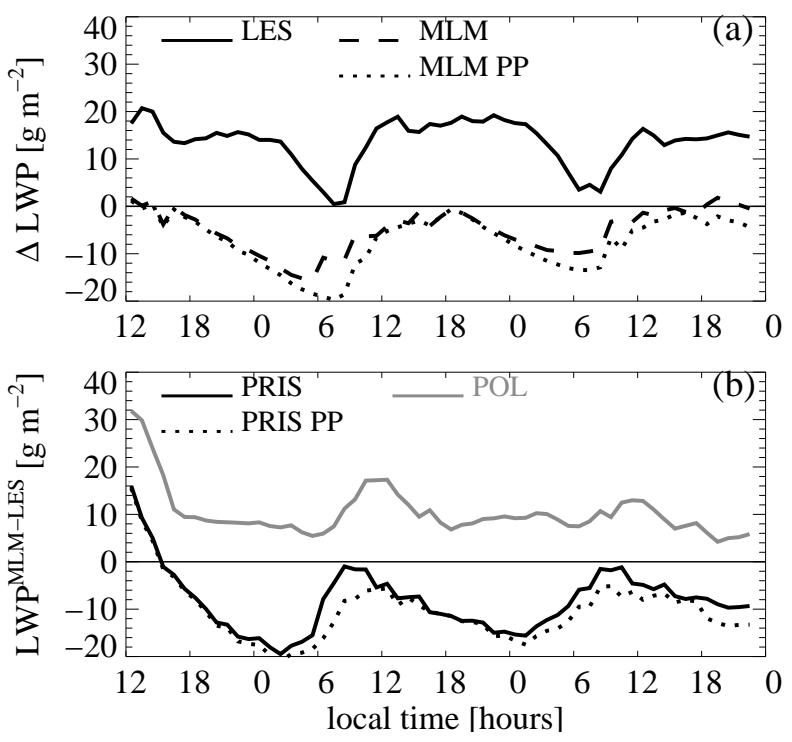

Fig. 8. (a) Time evolution of the difference between the LWPs of the pristine and the polluted STBLs, for the LES simulations in the case with fixed boundary conditions (full line) and for the corresponding integrations of the MLM, with (dotted) and without (dashed) parameterization of precipitation at the surface. (b) Time evolution of the difference in LWP between the MLM and the LES simulations for the polluted (grey) and for pristine STBLs (black) in the case with fixed boundary conditions. The dotted and full black lines correspond to integrations of the MLM with and without parameterization of precipitation at the surface, respectively.

The sign of the difference in LWP between a pristine and a polluted STBL predicted by the MLM is always the opposite of the one predicted with LES, and the bulk parameterization of the precipitation at the surface does not improve the results. Thus, contrary to the results of the LES, the MLM predicts that the polluted cloud always contains more water than the pristine one, and this tendency is the same for the three sets of simulations (Fig. 9). Indeed, the MLM almost always overestimates the LWP of the polluted cloud and underestimates the LWP of the pristine one (Fig. 8b). These differences are consistent with the differences we saw in the diagnostic evaluation of the mixed-layer model, wherein the biases in entrainment tended to moisten the polluted clouds and dry the pristine clouds, in contradiction to the LES results.

\section{Conclusions}

Three sets of $72 \mathrm{~h}$ LES of marine stratocumulus have been performed to cover a broad range of external forcing, in term of sea surface temperature and subsidence from above. Each set comprises a pair of simulations, the first one with a low CCN concentration, hence a low CDNC, that mostly precipitate, and the second one with a higher $\mathrm{CCN}$ concentration, 


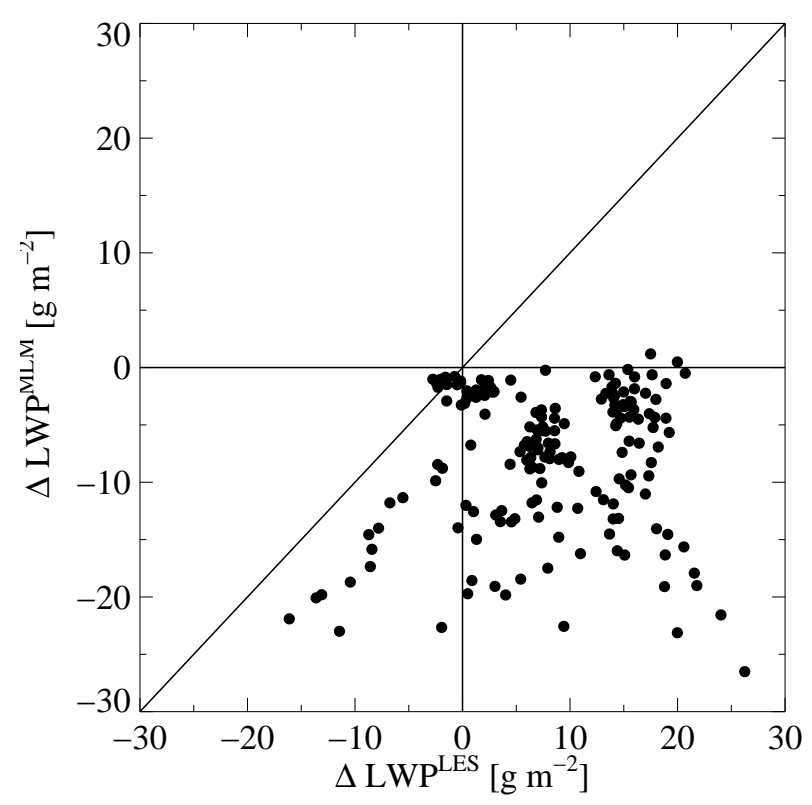

Fig. 9. Difference between the LWPs of the pristine and the polluted STBLs (hourly means, in $\mathrm{g} \mathrm{m}^{-2}$ ) predicted by the MLM against the same difference derived from the LES simulations for the three pairs of simulations.

hence greater CDNC, in which precipitation is inhibited. To varying degrees these simulations show that the LWP of the non-precipitating boundary layer is lower than the LWP of a precipitating one exposed to the same external forcing, quite in contrast to the simple models often introduced to explore indirect effects of the aerosol (Quaas et al., 2004; Lohmann and Feichter, 2005).

Given these simulations we then ask the question: Would the simplest, consistent model of the marine boundary layer (i.e., the mixed-layer model) be able to replicate this behavior of the LES? To answer this question each simulation has been analyzed and the bulk properties of the mixed-layer equivalent to the mean 3-D STBL have been derived, at $10 \mathrm{~min}$ intervals. These equivalent profiles have then been used to diagnose the LWP one would expect to find in a mixed-layer with the same mean state. Not surprisingly, the EML overestimates the LWP compared to its LES counterpart, especially when the LES simulated boundary layer is decoupled. As the decouplings appear at different times of the day in a precipitating and a non-precipitating STBL and their intensities are also different, the difference in LWP between the two clouds is not correctly diagnosed with the ML assumption. That said the biases are systematic in that they impact both the pristine and polluted simulations similarly, albeit not commensurately.

The parameterizations of the energy fluxes at the interfaces, that have been developed for boundary layer schemes, have then been evaluated. We also evaluated the parameter- ization of the entrainment rate at cloud top, as this has long been an issue of concern. We find that biases in the representation of entrainment by the mixed-layer framework are most strongly related to the presence of precipitation, either via the modification of the LWC vertical profile by droplets and drizzle drops sedimentation, or via the release of latent heat due to drizzle evaporation below cloud base. As a consequence, the warming and the drying of the STBL associated with cloud top entrainment is overestimated by the mixedlayer model when precipitation is active, hence the LWP tendency is underestimated. Attempts to address this shortcoming through the use of entrainment schemes that incorporate the effects of cloud-droplet sedimentation were unsuccessful, perhaps because even such schemes were not designed to incorporate the differing dynamics that arise when precipitation becomes active.

To investigate which one of these two contrasting tendencies dominates, i.e. the LWP overestimation for a specified bulk state of the boundary layer, and the underestimation of the LWP evolution, the MLM has been allowed to evolve freely, based on its own parameterizations. In this case, the LWP of the precipitating boundary layer is systematically underestimated (indicative of too much entrainment), while the one of the non-precipitating STBL is overestimated, so that the sign of the difference in LWP between the two clouds is the opposite of what the LES indicate.

This exercise therefore suggests that the deviations of the vertical structure from a well mixed-layer are key ingredients to the response of marine stratocumulus to changes in the aerosol loading. Such deviations should hence be properly represented by the parameterizations of cloudy boundary layers in order to correctly predict the aerosol impacts on these clouds and thus to reduce the uncertainties of aerosol indirect effects in climate change predictions. One way to do this would be to build in information about the evolution of the vertical structure within the bulk approach that serves as a starting point for the mixed-layer model.

Acknowledgements. Irina Sandu, Odile Thouron, and JeanLouis Brenguier acknowledge the support of Météo-France and CNRS. This work has been partly funded by EUCAARI (European Integrated project on Aerosol Cloud Climate and Air Quality interactions) No. 036833-2. We also thank the three anonymous reviewers for their comments and suggestions, which considerably improved the final manuscript.

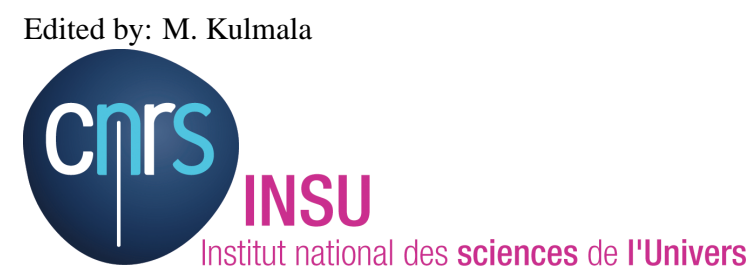

This Open Access Publication is financed by CNRS-INSU and the Max Planck Society. 


\section{References}

Ackerman, A. S., Kirkpatrick, M. P., Stevens, D. E., and Toon, O. B.: The impact of humidity above stratiform clouds on indirect aerosol climate forcing, Nature, 432, 1014-1017, 2004.

Albrecht, B.: Effects of Precipitation on the Thermodynamic Structure of the Trade Wind Boundary Layer, J. Geophys. Res., 98(D4), 7327-7337, 1993.

Barker, H. and Davies, J. A.: Solar radiative fluxes for stochastic, scale-invariant broken cloud fields, J. Atmos. Sci., 49, 11151126, 1992.

Bougeault, P.: The diurnal cycle of marine stratocumulus: A higher order model study, J. Atmos. Sci., 42, 2826-2843, 1985.

Bretherton, C. S. and Wyant, M. C.: Moisture transport, lowertroposphere stability, and decoupling of cloud-topped boundary, J. Atmos. Sci., 54, 148-167, 1997.

Bretherton, C. S., Blossey, P. N., and Uchida, J.: Cloud droplet sedimentation, entrainment efficiency, and subtropical stratocumulus albedo, Geophys. Res. Lett., 34, L03813, doi:10.1029/2006GL027648, 2007.

Caldwell, P., Bretherton, C. S., and Wood, R.: Mixed-Layer Budget Analysis of the Diurnal Cycle of Entrainment in Southeast Pacific Stratocumulus, J. Atmos. Sci., 62, 3775-3791, 2005.

Caldwell, P. and Bretherton, C. S.: Response of a Subtropical Stratocumulus-Capped Mixed Layer to Climate and Aerosol Changes, J. Climate, 22, 20-38, 2009.

Cohard, J. M., Pinty, J. P., and Shure, K.: On the parameterization of activation spectra from cloud condensation nuclei microphysical properties, J. Geophys. Res., 105, 11753-11766, 2000a.

Colella, P. and Woodward, P. R.: The Piecewise Parabolic Method (PPM) for Gas-Dynamical Simulations, J. Comput. Phys., 54, 174-201, 1986.

Duynkerke, P. G., de Roode, S. R., van Zanten, M. C., Calvo, J., Cuxart, J., Cheinet, S., Chlond, A., Grenier, H., Jonker, P. J., Kohler, M., Lenderink, G., Lewellen, D., Lappen, C.-L., Lock, A. P., Moeng, C.-H., Muller, F., Olmeda, D., Piriou, J.-M., Sanchez, E., and Sednev, I.: Observations and numerical simulations of the diurnal cycle of the EUROCS stratocumulus case, Q. J. Roy. Meteor. Soc., 604, 3269-3296, 2004.

Feingold, G., Stevens, B., Cotton, W. R., and Frisch, A. S.: On the relationship between drop in-cloud residence time and drizzle production in stratocumulus clouds, J. Atmos. Sci., 53, 11081122, 1996.

Geoffroy, O.: Modélisation LES des précipitations dans les nuages de couche limite et paramétrisation pour les modèles de circulation générale, Thèse de Doctorat, 2007.

Geoffroy, O., Brenguier, J.-L., and Sandu, I.: Relationship between drizzle rate, liquid water path and droplet concentration at the scale of a stratocumulus cloud system, Atmos. Chem. Phys., 8, 4641-4654, 2008,

http://www.atmos-chem-phys.net/8/4641/2008/.

Khairoutdinov, M. and Kogan, Y.: A New Cloud Physics Parameterization in a Large-Eddy Simulation Model of Marine Stratocumulus, Mon. Weather Rev., 128, 229-243, 2000.

Klein, S. A. and Hartmann, D. L.: The Seasonal Cycle of Low Stratiform Clouds, J. Climate, 6, 1587-1606, 1993.

Klein, S. A. and Norris, J. R.: On the Relationships among LowCloud Structure, Sea Surface Temperature, and Atmospheric Circulation in the Summertime Northeast Pacific, J. Climate, 8, 1140-1155, 1995.
Konor, C. and Arakawa, A.: Incorporation of moist processes and a PBL parameterization into the generalized vertical coordinate model, Technical report 102, UCLA, Department of Atmospheric Sciences, Box 951565, Los Angeles CA 90095-1565, USA, 66 pp., 2001.

Krueger, S. K., McLean, G. T., and Fu, Q.: Numerical Simulation of the Stratus-to-Cumulus Transition in the Subtropical Marine Boundary Layer. Part I: Boundary-Layer Structure, J. Atmos. Sci., 52, 2839-2850, 1995.

Lafore, J. P., Stein, J., Asencio, N., Bougeault, P., Ducrocq, V., Duron, J., Fischer, C., Héreil, P., Mascart, P., Masson, V., Pinty, J. P., Redelsperger, J. L., Richard, E., and Vilá-Guerau de Arellano, J.: The Meso-NH Atmospheric Simulation System. Part I: adiabatic formulation and control simulations, Ann. Geophys., 16, 90-109, 1998, http://www.ann-geophys.net/16/90/1998/.

Lilly, D. K.: Models of cloud topped mixed layers under a strong inversion, Q. J. Roy. Meteor. Soc., 94, 292-309, 1968.

Lilly, D. K.: Entrainment into mixed layers. Part II: A new closure, J. Atmos. Sci., 59, 3353-3361, 2002.

Lilly, D. K.: Validation of a mixed-layer closure. Part II: Observational tests, Q. J. Roy. Meteor. Soc., 134, 57-67, 2008.

Lilly, D. K. and Stevens, B.: Validation of a mixed-layer closure. Part I: Theoretical tests, Q. J. Roy. Meteor. Soc., 134, 47-55, 2008.

Lock, A.: The parameterization of entrainment in cloudy boundary layers, Q. J. Roy. Meteorol. Soc., 124, 2729-2753, 1998.

Lohmann, U. and Feichter, J.: Global indirect aerosol effects: a review, Atmos. Chem. Phys., 5, 715-737, 2005, http://www.atmos-chem-phys.net/5/715/2005/.

Lu, M. L. and Seinfeld, J. H.: Study of the aerosol indirect effect by Large-Eddy Simulation of marine stratocumulus, J. Atmos. Sci., 62, 3909-3932, 2005.

Moeng, C.: Entrainment rate, cloud fraction, and Liquid Water Path of PBL stratocumulus clouds, J. Atmos. Sci., 57, 3627-3643, 2000.

Morcrette, J.: Radiation and cloud radiative properties in the ECMWF operational weather forecast model, J. Geophys. Res., 96, 9121-9132, 1991.

Neiburger, M.: The relation of air mass structure to the field of motion over the eastern North Pacific Ocean in summer, Tellus, 12, 31-40, 1960.

Nicholls, S.: The dynamics of stratocumulus, Q. J. Roy. Meteor. Soc., 110, 821-845, 1984.

Pincus, R., Baker, M., and Bretherton, C.: What controls stratocumulus radiation properties? Lagrangian observations of cloud evolution, J. Atmos. Sci., 54, 2215-2236, 1997.

Quaas, J., Boucher, O., and Bréon, F.-M.: Aerosol indirect effects in POLDER sattelite data and the Laboratoire de Météorologie Dynamique-Zoom (LMDZ) general circulation model, J. Geophys. Res., 109, D08205, doi:10.1029/2003JD004 317, 2004.

Sandu, I., Brenguier, J. L., Geoffroy, O., Thouron, O., and Masson, V.: Aerosol impacts on the diurnal cycle of marine stratocumulus, J. Atmos. Sci., 65, 2705-2718, 2008.

Savic-Jovcic, V. and Stevens, B.: The structure and mesoscale organization of precipitating stratocumulus, J. Atmos. Sci., 65, 15871605, 2008.

Schubert, W., Wakefield, J. S., Steiner, E. J., and Cox, S. K.: Marine Stratocumulus Convection. part II: Horizontally Inhomogeneous 
Solutions, J. Atmos. Sci., 36, 1309-1324, 1979.

Stevens, B.: Cloud-transitions and decoupling in shear-free stratocumulus topped boundary layers, Geophys. Res. Lett., 27, 2557-2560, 2000a.

Stevens, B.: Entrainment in Stratocumulus Topped Mixed Layers, Q. J. Roy. Meteor. Soc., 128, 2663-2690, 2002.

Stevens, B.: Atmospheric Moist Convection, Annu. Earth Planet. Sci, 32, 605-643, 2005.

Stevens, B., Cotton, W. C., Feingold, G., and Moeng, C.-H.: Largeeddy Simulations strongly precipitating, shallow, stratocumulustopped boundary layers, J. Atmos. Sci., 55, 3616-3638, 1998.

Turton, J. and Nicholls, S.: A study of the diurnal variation of stratocumulus using a multiple mixed-layer model, Q. J. Roy. Meteor. Soc., 113, 969-1011, 1987.
Wood, R.: Cancellation of aerosol indirect effects in marine stratocumulus through cloud thinning, J. Atmos. Sci., 64, 26572669, 2007.

Wood, R., Bretherton, C. S., and Hartmann, D. L.: Diurnal cycle of liquid water path over subtropical and tropcal oceans, Geophysical Res. Let., 29, 2092, doi:10.1029/2002GL015371, 2002.

Wyant, M., Bretherton, C., Rand, H., and Stevens, D.: Numerical simulations and a conceptual model of the subtropical marine stratocumulus to trade cumulus, J. Atmos. Sci., 54, 168-192, 1997.

Zhang, Y., Stevens, B., and Ghil, M.: On the diurnal cycle and susceptibility to aerosol concentration in a stratocumulus-topped mixed layer, Q. J. Roy. Meteor. Soc., 131, 1567-1583, 2005. 